\title{
Amyloid tracers binding sites in autosomal dominant and sporadic Alzheimer's disease
}

\section{Ni, Ruiqing}

2017-04

$\mathrm{Ni}, \mathrm{R}$, Gillberg , P-G , Bogdanovic , N , Viitanen , M , Myllykangas , L, Nennesmo , I , Langstrom , B \& Nordberg , A 2017 , ' Amyloid tracers binding sites in autosomal dominant and sporadic Alzheimer's disease ' , Alzheimer's \& Dementia , vol. 13 , no. 4 , pp. 419-430 . https://doi.org/10.1016/j.

http://hdl.handle.net/10138/236747

https://doi.org/10.1016/j.jalz.2016.08.006

publishedVersion

Downloaded from Helda, University of Helsinki institutional repository.

This is an electronic reprint of the original article.

This reprint may differ from the original in pagination and typographic detail.

Please cite the original version. 


\title{
Amyloid tracers binding sites in autosomal dominant and sporadic Alzheimer's disease
}

\author{
Ruiqing Ni ${ }^{\mathrm{a}}$, Per-Göran Gillberg ${ }^{\mathrm{a}}$, Nenad Bogdanovic ${ }^{\mathrm{b}, \mathrm{c}}$, Matti Viitanen ${ }^{\mathrm{b}, \mathrm{d}}$, Liisa Myllykangas ${ }^{\mathrm{e}}$, \\ Inger Nennesmo ${ }^{\mathrm{f}}$, Bengt Långström ${ }^{\mathrm{g}}$, Agneta Nordberg ${ }^{\mathrm{a}, \mathrm{d}, *}$ \\ ${ }^{a}$ Division of Translational Alzheimer Neurobiology, Department of Neurobiology Care Sciences and Society, Center for Alzheimer Research, Karolinska \\ Institutet, Stockholm, Sweden \\ ${ }^{b}$ Division of Clinical Geriatrics, Department of Neurobiology Care Sciences and Society, Center for Alzheimer Research, Karolinska Institutet, Stockholm, \\ Sweden \\ ${ }^{c}$ Department of Geriatric Medicine, University of Oslo, Oslo, Norway \\ ${ }^{d}$ Department of Geriatric Medicine, Karolinska University Hospital Huddinge, Stockholm, Sweden \\ ${ }^{e}$ Department of Pathology, University of Helsinki, Helsinki, Finland \\ ${ }^{f}$ Division of Pathology, Department of Laboratory Medicine, Karolinska University Hospital Huddinge, Stockholm, Sweden \\ ${ }^{g}$ Department of Chemistry, Uppsala University, Uppsala, Sweden
}

\begin{abstract}
Introduction: Amyloid imaging has been integrated into diagnostic criteria for Alzheimer's disease (AD). How amyloid tracers binding differ for different tracer structures and amyloid- $\beta$ aggregates in autosomal dominant $\mathrm{AD}(\mathrm{ADAD})$ and sporadic $\mathrm{AD}$ is unclear.

Methods: Binding properties of different amyloid tracers were examined in brain homogenates from six ADAD with APPswe, PS1 M146V, and PS1 EA9 mutations, 13 sporadic AD, and 14 control cases. Results: ${ }^{3} \mathrm{H}$-PIB,${ }^{3} \mathrm{H}$-florbetaben, ${ }^{3} \mathrm{H}$-AZD2184, and BTA-1 shared a high- and a varying low-affinity binding site in the frontal cortex of sporadic AD. AZD2184 detected another binding site (affinity $33 \mathrm{nM}$ ) in the frontal cortex of ADAD. The ${ }^{3} \mathrm{H}$-AZD2184 and ${ }^{3} \mathrm{H}-\mathrm{PIB}$ binding were significantly higher in the striatum of ADAD compared to sporadic AD and control. Polyphenol resveratrol showed strongest inhibition on ${ }^{3} \mathrm{H}$-AZD84 binding followed by ${ }^{3} \mathrm{H}$-florbetaben and minimal on ${ }^{3} \mathrm{H}-\mathrm{PIB}$.
\end{abstract}

Discussion: This study implies amyloid tracers of different structures detect different sites on amyloid- $\beta$ fibrils or conformations.

(C) 2016 the Alzheimer's Association. Published by Elsevier Inc. All rights reserved.

Keywords: $\quad$ Alzheimer's disease; Amyloid- $\beta$; Autosomal dominant Alzheimer's disease; Positron emission tomography; Resveratrol; Pittsburgh compound B; AZD2184; Florbetaben

\section{Introduction}

The rapid development of molecular imaging enables measurement of brain amyloid- $\beta(\mathrm{A} \beta)$ plaques in vivo and facilitates an early detection of AD [1]. From the initial amyloid PET studies with ${ }^{11} \mathrm{C}$-Pittsburgh compound B (PIB), three PET tracers ${ }^{18} \mathrm{~F}$-florbetapir, ${ }^{18} \mathrm{~F}$-florbetaben, and ${ }^{18} \mathrm{~F}$ flutemetamol have been approved by US Food and Drug Administration and European Medical Association for use in clinical assessment of memory impairment to exclude AD.

*Corresponding author. Tel.: +468585 85467; Fax: +46858585470.

E-mail address: Agneta.K.Nordberg@ki.se
Subjects clinically diagnosed with $\mathrm{AD}$ without $\mathrm{A} \beta$ plaques at autopsy or PIB PET negative AD patients included in $A \beta$ immunization trials [2] raise the questions of clinical variants of $\mathrm{AD}$ or misdiagnosis of $\mathrm{AD}$. Appropriate use of biomarkers such as $A \beta$ PET will improve diagnostic accuracy. $A \beta$ tracers might vary in their binding properties to different $A \beta$ fibrils and thereby provide new insight into pathophysiological mechanisms and variants of AD. In silico modeling studies have suggested six different surface and core binding sites on synthetic $A \beta$ fibrils similarly using thioflavine-T compound (e.g., PIB), florbetaben, and florbetapir [3-5]. Three binding sites have been demonstrated on synthetic $A \beta$ fibrils [6]. A multiple-binding site model for $A \beta$ tracers was 
suggested in $\mathrm{AD}$ autopsy brain where florbetapir, florbetaben, and PIB mainly bind to a high-affinity site 1 (nanomolar range), BF-227 mainly with low-affinity to site 3, and FDDNP partly binding to site 2 [7].

Autosomal dominant AD (ADAD) [8] characterized by atypical forms of $\mathrm{A} \beta$ aggregates represents interesting models to study target engagement of $A \beta$ tracer to fibrillar as well as other $\mathrm{A} \beta$ conformations. Prominent ${ }^{11} \mathrm{C}$-PIB retentions have been reported in ADAD carrying PSI and APP mutation, in cortical and particularly subcortical brain regions [9-15]. In two exceptions, APParc [13] and APPE 6993 [16], low cortical ${ }^{11} \mathrm{C}$-PIB retention was reported compared to sporadic $\mathrm{AD}(\mathrm{sAD})$ probably due to ring-shaped plaques or oligomeric $A \beta$ accumulation in the brain.

In the present study, we compared the binding characteristics of A $\beta$ PET tracers ${ }^{3} \mathrm{H}$-PIB,${ }^{3} \mathrm{H}$-AZD $2184,{ }^{3} \mathrm{H}$-florbetaben, and methyl- ${ }^{3} \mathrm{H}-\mathrm{BTA}-1$ in autopsy brain tissues from the frontal cortex and striatum of patients with $\mathrm{SAD}$ and $\mathrm{ADAD}$, respectively. An additional third binding site was detected by AZD2184 in the frontal cortex of ADAD patients as opposite to the other A $\beta$ tracers. High AZD2184 and PIB binding were measured in the striatum of ADAD compared to sAD. In addition, AZD2184 competed in nanomolar range with anti-A $\beta$ phenol compound resveratrol. The $A \beta$ binding properties seem to depend both on the chemical structures of $A \beta$ tracers as well as the conformation of $A \beta$ aggregates.

\section{Methods}

\subsection{Materials}

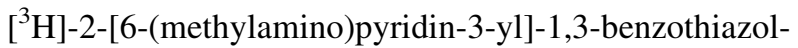
6-ol $\left({ }^{3} \mathrm{H}-\mathrm{AZD} 2184\right.$, specific activity (SA) $\left.21.9 \mathrm{Ci} / \mathrm{mmol}\right)$ and AZD2184 were synthesized at the Karolinska Institutet PET Radiochemistry Laboratory, Stockholm, Sweden. $\left[\mathrm{N}\right.$-methyl- $\left.{ }^{3} \mathrm{H}\right] 2-(4$ '-methylaminophenyl)-6-hydroxybenzothiazole $\left({ }^{3} \mathrm{H}-\mathrm{PIB}\right.$, SA $85 \mathrm{Ci} / \mathrm{mmol}$ ) and Methyl- ${ }^{3} \mathrm{H}-\mathrm{BTA}-1$, (SA $84 \mathrm{Ci} / \mathrm{mmol}$ ) were synthesized by Quotient Bioresearch, Cardiff, UK. [N-methyl- $\left.{ }^{3} \mathrm{H}\right] 4-[(\mathrm{E})-2-(4-\{2-[2-(2-$ fluoroethoxy) ethyl]ethoxy \}phenyl) ethenyl]-aniline $\left({ }^{3} \mathrm{H}\right.$-florbetaben, SA $63 \mathrm{Ci} / \mathrm{mmol}$ ) and florbetaben were synthesized by
Bayer Healthcare Pharmaceuticals, Berlin, Germany. 2-(4'-Methylaminophenyl)benzothiazole (BTA-1) and 4,5trihydroxy-trans-stilbene (resveratrol) were purchased from Sigma Aldrich, MO. Fig. 6 showed the chemical structures of amyloid tracers and resveratrol drawn using ChemDraw Standard 14.0 (CambridgeSoft, Perkin Elmer, MA).

\subsection{Sporadic $A D, A D A D$, and control brain studies}

Frontal cortex and striatum (caudate nucleus and putamen) tissues from 13 patients with SAD (mean age, $68.2 \pm 8.5 \mathrm{y}$ ), clinically diagnosed and confirmed by pathologic examination according to NINCDS-ADRDA criteria, and 14 age-matched controls (mean age $74.1 \pm 12.0$ y) were obtained at autopsy and provided by the Netherlands Brain Bank, Netherlands Institute for Brain Research, Amsterdam, Netherland (Table 1). Brain tissues from six ADAD cases including three APPswe mutation carriers (mean age $63.3 \pm 3.7 \mathrm{y}$ ) and one PS1 M146V mutation carrier (age 48 y) were provided by the Brain Bank at Karolinska Institutet, Stockholm, Sweden. Brain tissues from one PS1 M146V mutation carrier (age, 43 years) and one PSI EA9 mutation carrier (age, 66 years) were provided from the Department of Pathology, University of Helsinki, Helsinki, Finland. Permission to use autopsy brain material in experimental procedures was granted by the Regional Human Ethics committee in Stockholm and the Swedish Ministry of Health and Ethics Committee of the Northern Ostrobothnia Hospital District, Finland. Brain regions were dissected following the recommendation of BrainNet Europe for fixation and anatomic dissection (www.brainnet-europe.org).

\subsection{Bielschowsky silver staining in ADAD and sporadic Alzheimer's cases}

For neuropathological investigations, brain tissues from ADAD and SAD were fixed in buffered $4 \%$ formaldehyde for 4-6 weeks, paraffinized, and cut to 5- $\mu \mathrm{m}$ thick sections from the frontal medial gyrus and striatum. The sections were stained in the same laboratory condition by Bielschowsky silver impregnation according to Yamamoto modification [17].

Table 1

Demographic information for sporadic and autosomal dominant Alzheimer's disease cases

\begin{tabular}{|c|c|c|c|c|c|c|}
\hline Cohort & $\mathrm{N}$ & Age (range) & $\operatorname{Sex}(\mathrm{F} / \mathrm{M})$ & APOE $\varepsilon 4(0 / 1 / 2)$ & Disease duration (y) & Postmortem delay (h) \\
\hline sAD & 13 & $68.9 \pm 8.5(58-81)$ & $7 / 6$ & $3 / 3 / 7$ & $6.1 \pm 3.2$ & $5.0 \pm 0.9$ \\
\hline ADAD & 6 & $57.8 \pm 10.6(43-68)$ & $3 / 3$ & $4 / 1 / 1$ & $9.5 \pm 4.0$ & $19.6 \pm 8.7$ \\
\hline APPswe & 3 & $56-68$ & $0 / 3$ & $2 / 0 / 1$ & $9.3 \pm 2.2$ & $21.7 \pm 1.3$ \\
\hline PS1 M146V & 2 & $43-48$ & $2 / 0$ & $1 / 1 / 0$ & $4-10$ & 28 \\
\hline PS1 EA9 & 1 & 66 & $1 / 0$ & $1 / 0 / 0$ & 14 & 5 \\
\hline Ctrl & 14 & $74.1 \pm 12.0(50-88)$ & $5 / 9$ & $14 / 0 / 0$ & - & $7.3 \pm 3.8$ \\
\hline
\end{tabular}

Abbreviations: sAD, sporadic Alzheimer's disease; ADAD, autosomal dominant Alzheimer's disease; APPswe, Swedish APP mutation carrier; PS1 M146V, Presenilin 1 M146V mutation carrier; PS1 EA9, Presenilin 1 exon 9 deletion; Ctrl, healthy age-matched controls; APOE, apolipoprotein E; 0/1/2, number of $\varepsilon 4$ allele.

NOTE. Data are shown as mean \pm standard deviation (SD). 


\subsection{Saturation assays in the frontal cortex homogenates from sporadic $A D$}

Postmortem frontal cortex brain tissue homogenates (100- $\mu \mathrm{g}$ tissue) from patients with $\mathrm{SAD}$ were incubated with $0.01-250 \mathrm{nM}{ }^{3} \mathrm{H}-\mathrm{AZD} 2184,{ }^{3} \mathrm{H}-\mathrm{PIB},{ }^{3} \mathrm{H}$-florbetaben, and methyl- ${ }^{3} \mathrm{H}-\mathrm{BTA}-1$ in $1 \times$ PBS buffer $(\mathrm{pH}$ 7.4) for 2 hours at room temperature. Nonspecific binding was determined in the presence of $1-\mu \mathrm{M}$ BTA-1. Fig. 6 shows the chemical structures of the ligands. Samples were run in triplicates, and the specific binding was expressed in $\mathrm{pmol} / \mathrm{g}$ tissue. The dissociation constant $\left(\mathrm{K}_{\mathrm{d}}\right)$ and maximum number of binding sites $\left(\mathrm{B}_{\max }\right)$ were determined using nonlinear regression models in GraphPad Prism, version 6.0 (GraphPad Software, Inc., La Jolla, CA). The saturation data were fit to one-site and two-site binding model, followed by F-test for model selection. Scatchard plots were obtained using GraphPad Prism to display the saturation data.

\subsection{Competitive binding studies in frontal cortical and striatum homogenates from sporadic $A D$ and $A D A D$}

Competitive binding assays comparing different amyloid tracers in SAD frontal cortex brains were carried out by incubating homogenates $\left(100-\mu \mathrm{g}\right.$ tissue) with $1.0-\mathrm{nM}{ }^{3} \mathrm{H}-\mathrm{PIB}$, 2.5-nM ${ }^{3} \mathrm{H}$-florbetaben, $1.5-\mathrm{nM}{ }^{3} \mathrm{H}-\mathrm{AZD} 2184$, or $2.0-\mathrm{nM}$ methyl- ${ }^{3} \mathrm{H}-\mathrm{BTA}-1$ in the presence of unlabeled AZD2184, BTA-1, florbetaben and at concentrations ranging from $10^{-11}$ to $10^{-4} \mathrm{M}$. Competition binding assays comparing ${ }^{3} \mathrm{H}$-PIB binding properties in SAD and ADAD (APPswe, PS1 M146V, and PS1 E49) brain were carried out by incubating frontal cortex and striatum homogenates $(100 \mu \mathrm{g}$ tissue) with 1.0-nM ${ }^{3} \mathrm{H}-\mathrm{PIB}$ in the presence of BTA-1 and AZD2184 at concentrations ranging from $10^{-11}$ to $10^{-4} \mathrm{M}$. The affinity constant $\left(\mathrm{K}_{\mathrm{i}}\right)$ and percentage of displacement were determined by using nonlinear regression one-site and two-site binding models derived from ChengPrusoff equation in GraphPad Prism, followed by F-test for model selection. The three-site binding of ${ }^{3} \mathrm{H}-\mathrm{PIB} /$ AZD2184 competitive binding in the frontal cortex from ADAD was analyzed by additional fitting using two-site binding model in GraphPad Prism with binding data at AZD2184 concentration ranging from $10^{-9}$ to $10^{-4} \mathrm{M}$.

\subsection{Regional ${ }^{3} H$-PIB and ${ }^{3} H$-AZD 2184 binding in brain tissue homogenates from sporadic $A D, A D A D$, and healthy controls}

Single concentration binding studies using $1.0-\mathrm{nM}{ }^{3} \mathrm{H}-$ PIB and 1.5-nM ${ }^{3} \mathrm{H}-\mathrm{AZD} 2184$ were carried out by incubating homogenates $(200 \mu \mathrm{g}$ tissue) from the frontal cortex and striatum of sAD and ADAD (APPswe, PS1 M146V, PS1 E $\triangle 9$ mutation carriers) and control brains. Nonspecific binding was determined in the presence of $1-\mu \mathrm{M}$ BTA-1.

\subsection{Interaction of resveratrol on amyloid tracer binding in the frontal cortical homogenates from patients with sporadic $A D$}

To determine the influence of phenols on amyloid tracer binding, frontal cortex homogenates from three SAD were incubated with $1.5-\mathrm{nM}{ }^{3} \mathrm{H}-\mathrm{AZD} 2184,2.5-\mathrm{nM}{ }^{3} \mathrm{H}$-florbetaben, and 1.0-nM ${ }^{3} \mathrm{H}-\mathrm{PIB}$ in the presence of resveratrol at concentrations of $10^{-11}$ to $10^{-4} \mathrm{M}$.

\subsection{Statistical analysis}

Data were analyzed using GraphPad Prism, version 6.0. Nonparametric Mann-Whitney test was used for comparisons between groups. All values are shown as means \pm standard deviation (SD). Error bars in the figures represent standard error (SEM) values. Significant differences between groups were set at $* P<.05, * * P<.01$, and $* * * P<.001$.

\section{Results}

\subsection{Bielschowsky silver staining in sporadic $A D$ and $A D A D$}

Bielschowsky silver staining was performed in brain sections of APPswe, PS1 M146V, and PS1 EA9 cases. ADAD showed a more intensive neuritic plaque staining in the layer I-III of frontal medial gyrus compared to sporadic $\mathrm{AD}$ cases (Fig. 1A-1D). The largest plaques were observed in the cortex of PSI EA9 case reaching the size of $100-\mu \mathrm{m}$ in diameter. In PS1 M146V cases, neurofibrillary tangles and treads were less present, with the feature of heavy loaded silver-impregnated neuritic plaques indicating the presence of additional fibrillary pathology in the plaques. APPswe and PS1 M146V cases showed intensive silver impregnation in the striatum; whereas for PS1 EA9 cases as well as SAD cases, there was an abundance of plaques in the striatum although the silver staining was weaker indicating their more diffuse nature (Fig. 1E-1H).

\subsection{Comparison of the binding properties of different amyloid tracers in the frontal cortex and striatum of sporadic $A D$ and $A D A D$}

To characterize the binding sites of the amyloid tracers ${ }^{3} \mathrm{H}$-AZD2184, ${ }^{3} \mathrm{H}-\mathrm{PIB}, \quad{ }^{3} \mathrm{H}$-florbetaben, and methyl- ${ }^{3} \mathrm{H}-\mathrm{BTA}-1, \quad$ saturation-binding studies using increasing concentrations $(0.01-250 \mathrm{nM})$ of these tracers were performed in the frontal cortex homogenates from sAD patients. Fig. 2 illustrates the saturation curves and Scatchard plots. Two binding sites could be obtained for ${ }^{3} \mathrm{H}-\mathrm{AZD} 2184\left(\mathrm{~K}_{\mathrm{d}}: 6.5 \mathrm{nM}, 50.4 \mathrm{nM}\right),{ }^{3} \mathrm{H}-\mathrm{PIB}\left(\mathrm{K}_{\mathrm{d}}: 2.5 \mathrm{nM}\right.$, $81.7 \mathrm{nM})$, and ${ }^{3} \mathrm{H}$-florbetaben $\left(\mathrm{K}_{\mathrm{d}}: 9.7 \mathrm{nM}, 136 \mathrm{nM}\right)$, respectively. Comparable binding affinity $\left(\mathrm{K}_{\mathrm{d}}\right)$ for the high-affinity and low-affinity binding sites, and $\mathrm{B}_{\max }$ for the high-affinity 


\section{Biechowsky silver staining}

\section{Frontal cortex}
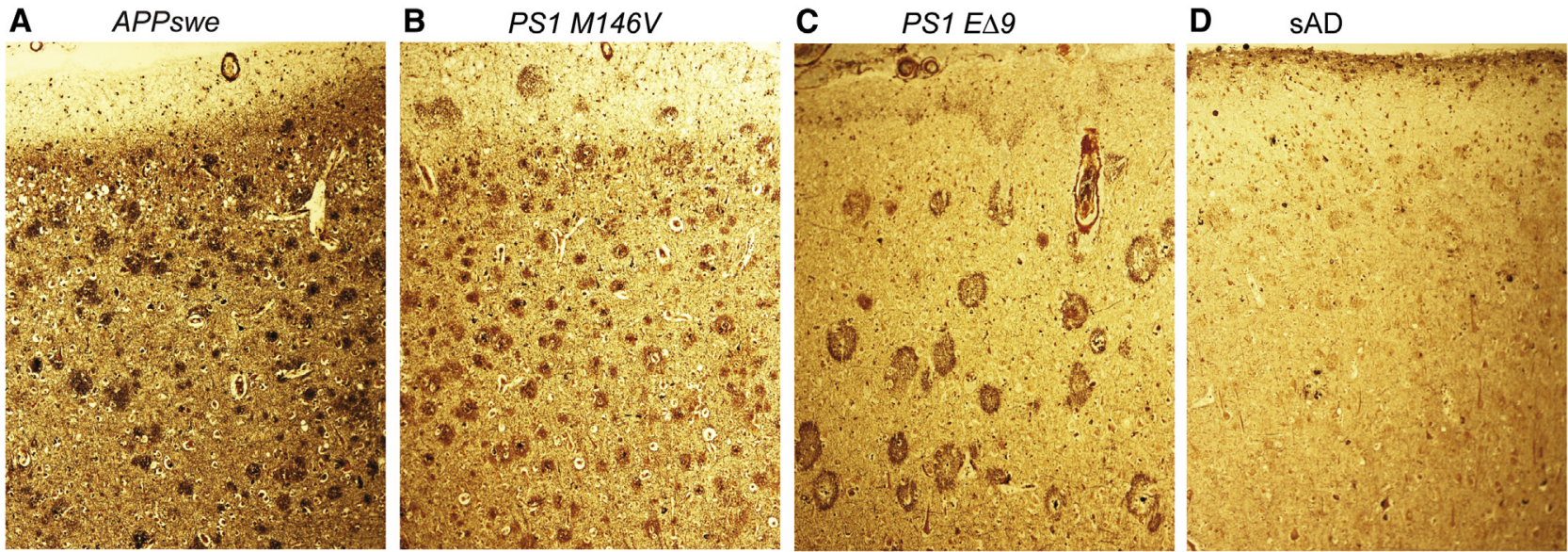

\section{Striatum}
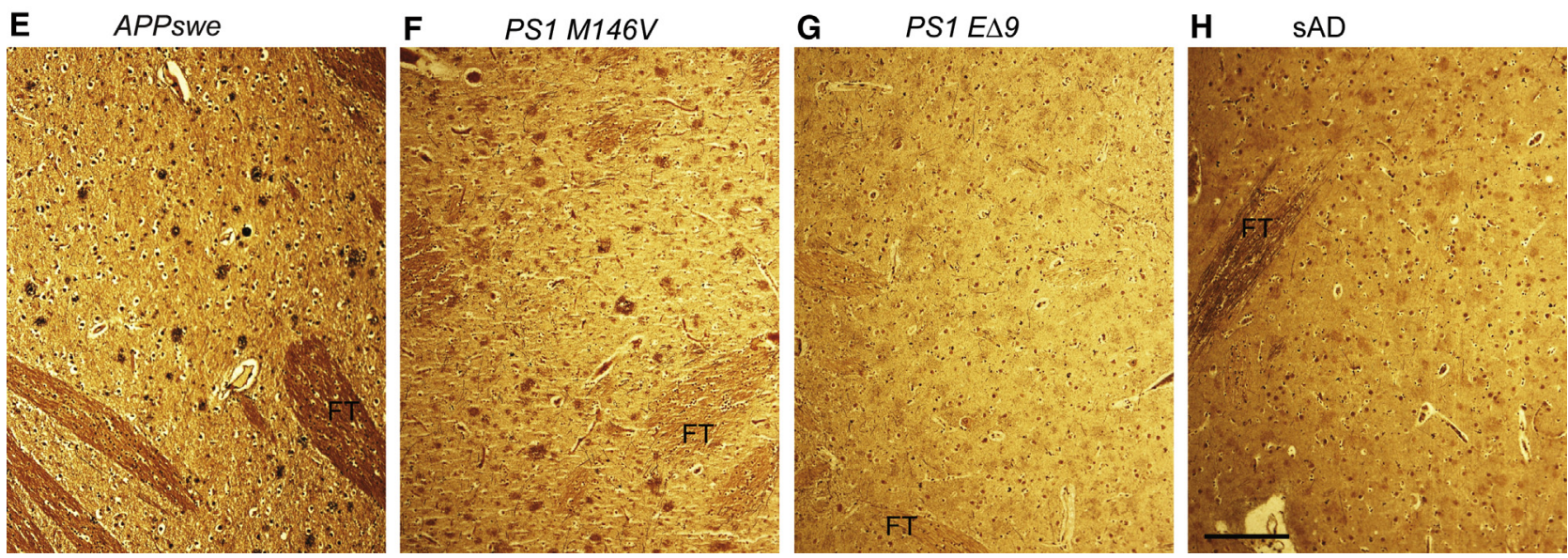

Fig. 1. Bielschowsky staining of the frontal medial gyrus, layers I-III (A-D) and striatum (E-H) in the brain slides from autosomal dominant Alzheimer's disease (APPswe, PS1 M146V, PS1 EA9 mutation carrier) and sporadic Alzheimer's disease (sAD). The most intensive silver impregnation was obtained in cortical layers of ADAD and in the striatum of APPswe, PS1 M146V, whereas striatum of PS1 E $\triangle 9$ has displayed weak staining indicating diffuse-like plaque structures. In the sporadic AD case, frontal cortex has expressed neuritic plaques less intensive than corresponding ADAD frontal cortex. In the striatum of sporadic AD case, diffuse plaques were dominant. In the section from striatum, the presence of fiber tracts (FT) indicates a proper anatomic level. Bar $=200 \mu \mathrm{m}$.

site was obtained for three amyloid tracers. No definite binding sites could be detected with the tracer methyl- ${ }^{3} \mathrm{H}-\mathrm{BTA}-1$ due to high percentage of nonspecific binding.

To further characterize and compare the binding properties of the amyloid tracers, competition studies were performed in the frontal cortex homogenates from SAD cases with ${ }^{3} \mathrm{H}$-AZD2184, ${ }^{3} \mathrm{H}$-PIB, ${ }^{3} \mathrm{H}$-florbetaben, and methyl- ${ }^{3} \mathrm{H}-\mathrm{BTA}-1$ in the presence of increasing concentrations of unlabeled BTA-1, AZD2184, and florbetaben $\left(10^{-11}\right.$ to $\left.10^{-4} \mathrm{M}\right)$, respectively. Analysis of the competition results demonstrated the presence of a similar high-affinity site and a varying low-affinity site of ${ }^{3} \mathrm{H}$-AZD $2184,{ }^{3} \mathrm{H}-\mathrm{PIB}$, and ${ }^{3} \mathrm{H}$-florbetaben in the SAD frontal cortex (Fig. 3).

${ }^{3} \mathrm{H}-\mathrm{PIB}$ showed two binding sites for unlabeled AZD2184 $\left(\mathrm{K}_{\mathrm{i}}: 0.1 \mathrm{nM}, 125 \mathrm{nM}\right)$, BTA-1 $\left(\mathrm{K}_{\mathrm{i}}: 0.9 \mathrm{nM}, 83 \mathrm{nM}\right)$, and florbetaben $\left(\mathrm{K}_{\mathrm{i}}: 0.1 \mathrm{nM}, 190 \mathrm{nM}\right)$ in the sAD frontal cortex.
${ }^{3} \mathrm{H}-\mathrm{AZD} 2184$ demonstrated a wide range of low-affinity binding sites with unlabeled AZD2184 $\left(\mathrm{K}_{\mathrm{i}}\right.$ : $0.1 \mathrm{nM}$, $7 \mathrm{nM})$, BTA-1 $\left(\mathrm{K}_{\mathrm{i}}: 0.1 \mathrm{nM}, 53 \mathrm{nM}\right)$, and florbetaben $\left(\mathrm{K}_{\mathrm{i}}\right.$ : $0.2 \mathrm{nM}, 325 \mathrm{nM}$ ). For ${ }^{3} \mathrm{H}$-florbetaben, two sites with comparable affinities were obtained with AZD2184 $\left(\mathrm{K}_{\mathrm{i}}: 0.5 \mathrm{nM}\right.$, $24 \mathrm{nM})$, BTA-1 $\left(\mathrm{K}_{\mathrm{i}}: 0.1 \mathrm{nM}, 45 \mathrm{nM}\right)$, and florbetaben $\left(\mathrm{K}_{\mathrm{i}}\right.$ : $0.1 \mathrm{nM}, 32 \mathrm{nM})$, respectively. Methyl- ${ }^{3} \mathrm{H}-\mathrm{BTA}-1$ binding contained high percentage of nonspecific component, and one binding site was estimated for florbetaben $(\approx 20 \mathrm{nM})$, AZD2184 ( $\approx 200 \mathrm{nM})$, and BTA-1 ( $\approx 1000 \mathrm{nM}$; Fig. 3$)$.

To investigate the difference between amyloid binding sites in ADAD and SAD brain, ${ }^{3} \mathrm{H}$-PIB competitive binding assays were performed using unlabeled AZD2184 or BTA-1 in the frontal cortex and striatum from six ADAD patients (including three APPswe, two PS1 M146V, and one PS1 $E \Delta 9$ mutation carriers). In the frontal cortex from ADAD, 


\section{sAD Frontal cortex}

A $^{3} \mathrm{H}-\mathrm{AZD} 2184$

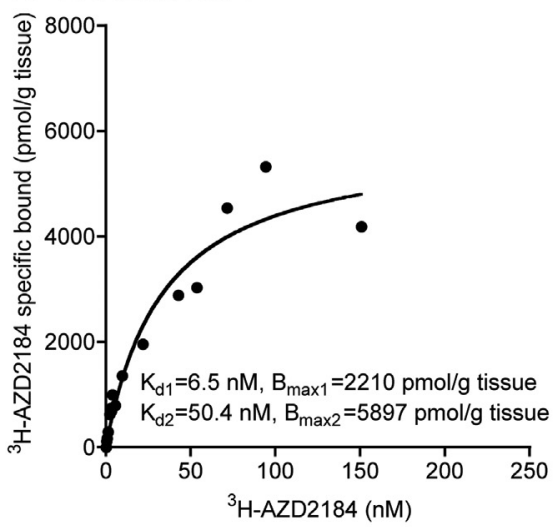

$\mathrm{C}^{3} \mathrm{H}-\mathrm{PIB}$

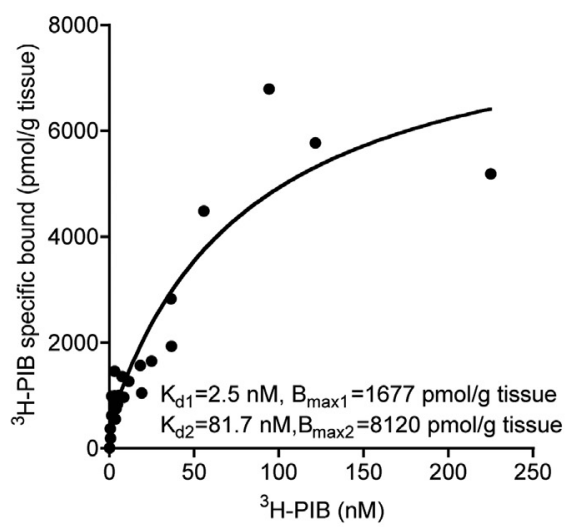

E ${ }^{3} \mathrm{H}$-florbetaben

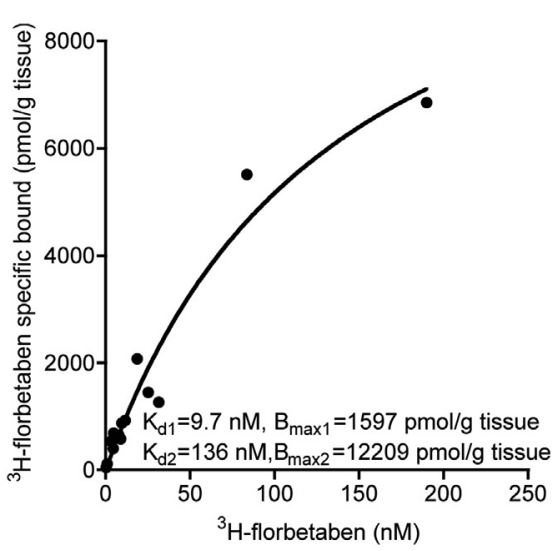

B

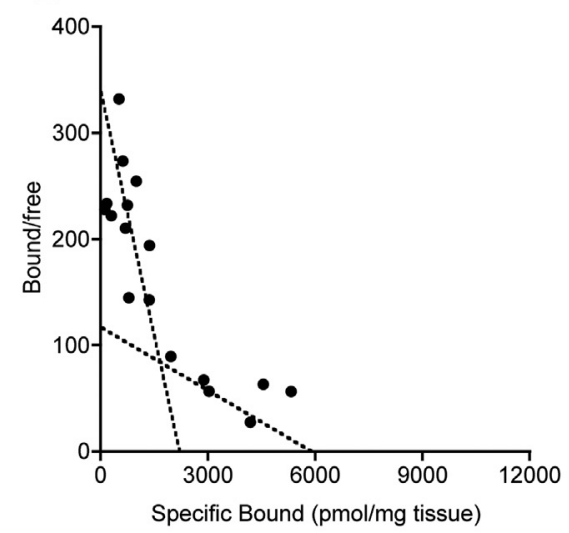

D
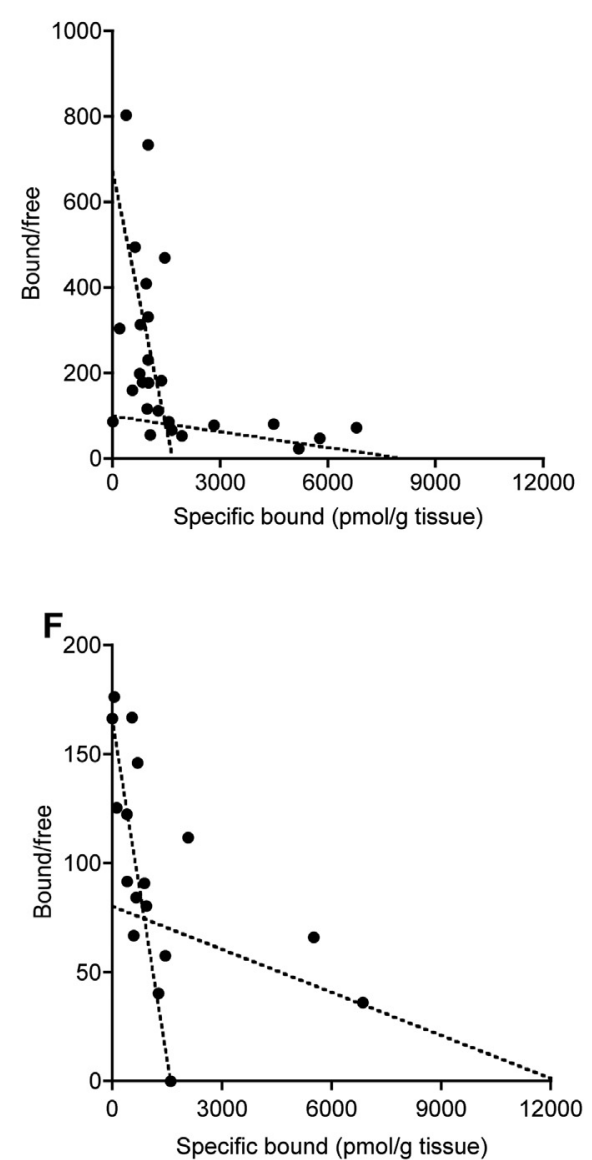

Fig. 2. Saturation binding of different amyloid tracers in the frontal cortics from sporadic Alzheimer's disease. (A, B) ${ }^{3} \mathrm{H}-\mathrm{AZD} 2184(0.1-150 \mathrm{nM}),(\mathrm{C}, \mathrm{D}){ }^{3} \mathrm{H}-$ PIB $(0.1-250 \mathrm{nM}),(\mathrm{E}, \mathrm{F})^{3} \mathrm{H}$-florbetaben $(0.1-200 \mathrm{nM})$ saturation in frontal cortices from sporadic Alzheimer's disease indicated a similar high-affinity and a low-affinity binding site for ${ }^{3} \mathrm{H}$-AZD2184 $\left(\mathrm{K}_{\mathrm{d} 1}=6.5 \mathrm{nM}, \mathrm{B}_{\max 1}=2210 \mathrm{pmol} / \mathrm{g}\right.$ tissue; $\mathrm{K}_{\mathrm{d} 2}=50.4 \mathrm{nM}, \mathrm{B}_{\max 2}=5897 \mathrm{pmol} / \mathrm{g}$ tissue $),{ }^{3} \mathrm{H}-\mathrm{PIB}\left(\mathrm{K}_{\mathrm{d} 1}=2.5 \mathrm{nM}\right.$, $\mathrm{B}_{\max 1}=1677 \mathrm{pmdol} / \mathrm{g}$ tissue; $\mathrm{K}_{\mathrm{d} 2}=81.7 \mathrm{nM}, \mathrm{B}_{\max 2}=8120 \mathrm{pmol} / \mathrm{g}$ tissue $),{ }^{3} \mathrm{H}$-florbetaben $\left(\mathrm{K}_{\mathrm{d} 1}=9.7 \mathrm{nM}, \mathrm{B}_{\max 1}=1597 \mathrm{pmol} / \mathrm{g}\right.$ tissue; $\mathrm{K}_{\mathrm{d} 2}=136 \mathrm{nM}$, $\mathrm{B}_{\max 2}=12,209 \mathrm{pmol} / \mathrm{g}$ tissue). Binding data were analyzed using GraphPrism non-linear regression fitting. Abbreviations: sAD, sporadic Alzheimer's disease; ${ }^{3} \mathrm{H}-\mathrm{PIB},{ }^{3} \mathrm{H}$-Pittsburgh compound B.

three binding sites were demonstrated using AZD2184 $\left(\mathrm{K}_{\mathrm{i}}\right.$ : $0.5 \mathrm{nM}, 33 \mathrm{nM}, 327 \mathrm{nM}$ ), whereas two binding sites with unlabeled BTA-1 ( $\mathrm{K}_{\mathrm{i}}: 1.3 \mathrm{nM}, 80 \mathrm{nM}$; Fig. 4A). In the striatum of ADAD, two binding sites were detected using AZD2184
$\left(\mathrm{K}_{\mathrm{i}}: 0.6 \mathrm{nM}, 95 \mathrm{nM}\right)$ and BTA-1 $\left(\mathrm{K}_{\mathrm{i}}: 0.8 \mathrm{nM}, 37 \mathrm{nM}\right)$. The ${ }^{3}$ H-PIB/BTA-1 binding affinity was somewhat higher in the striatum of ADAD cases compared to that of $\mathrm{SAD}\left(\mathrm{K}_{\mathrm{i}}\right.$ : $4.8 \mathrm{nM}, 105 \mathrm{nM}$; Fig. 4B). 


\section{sAD Frontal cortex}

A ${ }^{3} \mathrm{H}-\mathrm{AZD} 2184$

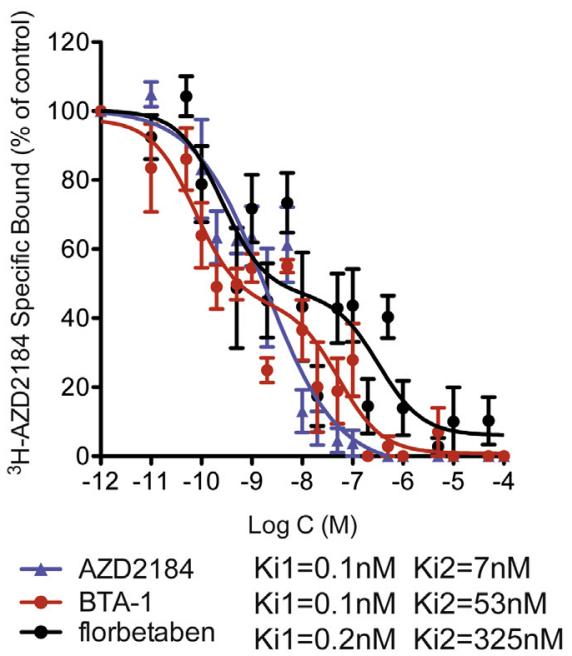

c ${ }^{3} \mathrm{H}$-florbetaben

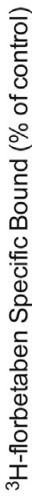

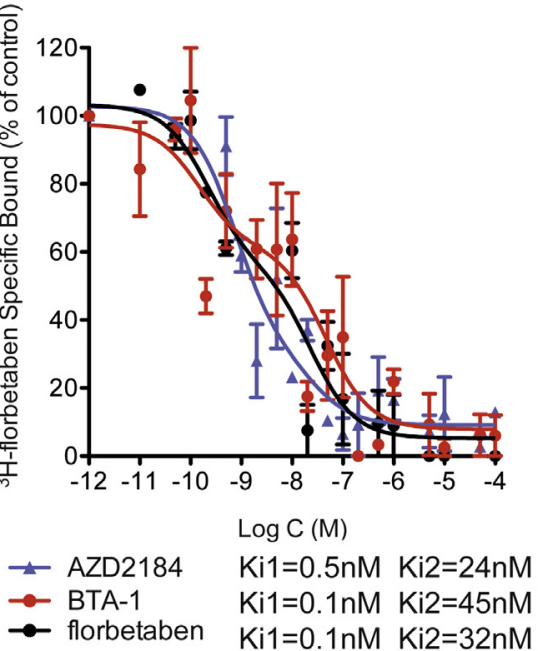

B ${ }^{3} \mathrm{H}-\mathrm{PIB}$

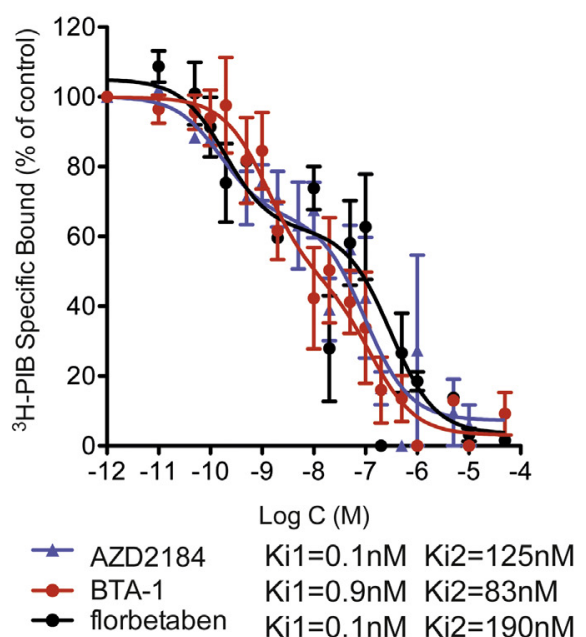

D ${ }^{3} \mathrm{H}-\mathrm{Me}-\mathrm{BTA}-1$

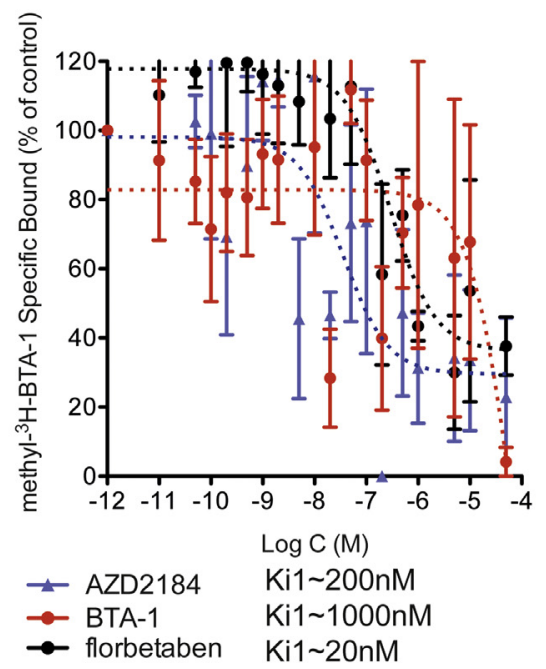

Fig. 3. Competitive binding of different amyloid tracers in the frontal cortics from sporadic Alzheimer's disease showing multiples binding sites. (A) ${ }^{3} \mathrm{H}-$ AZD2184 (1.5 nM), (B) ${ }^{3} \mathrm{H}$-PIB (1.0 nM), (C) ${ }^{3} \mathrm{H}$-florbetaben $(2.0 \mathrm{nM})$, and (D) ${ }^{3} \mathrm{H}-$ Methyl-BTA-1 (2.5 nM) binding displaced with unlabeled AZD2184 (blue), BTA-1 (red), florbetaben (black) at $10^{-12} \mathrm{M}-10^{-4} \mathrm{M}$ in the frontal cortices from sporadic Alzheimer's disease $(\mathrm{n}=3-6)$. Data are presented as means \pm standard error of the mean (SEM). Abbreviations: sAD, sporadic Alzheimer's disease; ${ }^{3} \mathrm{H}-\mathrm{PIB},{ }^{3} \mathrm{H}-\mathrm{Pittsburgh}$ compound B; ${ }^{3} \mathrm{H}-\mathrm{Me}-\mathrm{BTA}-1,{ }^{3} \mathrm{H}-$ Methyl-BTA-1

\subsection{Regional amyloid tracer binding in autosomal dominant and sporadic Alzheimer's disease}

The binding of a single concentration of ${ }^{3} \mathrm{H}-\mathrm{PIB}(1.0 \mathrm{nM})$ and ${ }^{3} \mathrm{H}$-AZD2184 $(1.5 \mathrm{nM})$ was measured in the homogenates from the frontal cortex and striatum of six ADAD cases (including three APPswe, two PS1 M146V, and one PS1 EA9 mutation carriers), $13 \mathrm{sAD}$ cases, and 14 controls respectively. Although the three ADAD mutations showed different properties of plaque pathology (Fig. $1 \mathrm{~A}-1 \mathrm{H}$ ), the ADAD cases were analyzed together due to few cases from each mutation. A significant higher number of ${ }^{3} \mathrm{H}-$ PIB and ${ }^{3} \mathrm{H}-\mathrm{AZD} 2184$ binding sites were observed in the frontal cortex of both ADAD and SAD cases compared to healthy controls (Table 2). A significant higher ${ }^{3} \mathrm{H}$-PIB as well as the ${ }^{3} \mathrm{H}$-AZD2184 binding was measured in the striatum of ADAD cases compared to control cases, whereas no significant difference in binding was observed between $\mathrm{SAD}$ and controls (Table 2). Of the ADAD cases, both cases with APPswe and PS1 M146V encoded mutations showed heavy plaque load in the striatum (Fig. 1E-1H). 
A ADAD Frontal cortex

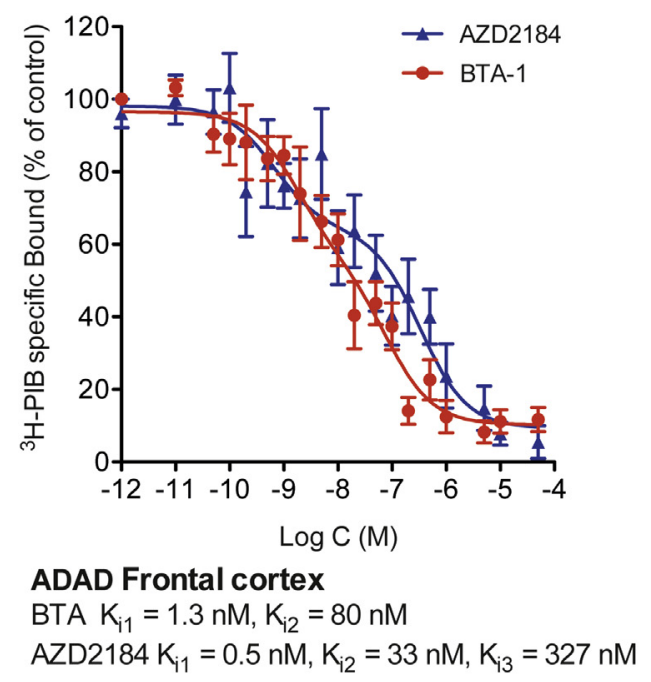

B $\quad A D A D$ and SAD Striatum

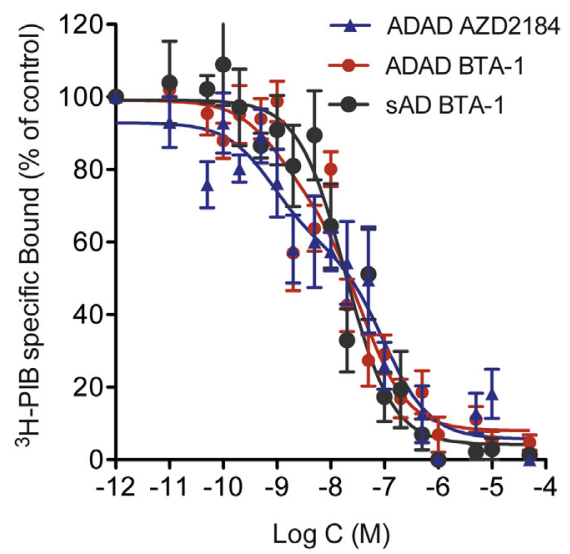

ADAD Striatum

BTA-1 $\mathrm{K}_{\mathrm{i} 1}=0.8 \mathrm{nM}, \mathrm{K}_{\mathrm{i} 2}=37 \mathrm{nM}$

$A Z D 2184 \mathrm{~K}_{\mathrm{i} 1}=0.6 \mathrm{nM}, \mathrm{K}_{\mathrm{i} 2}=95 \mathrm{nM}$

\section{SAD Striatum}

BTA-1 $\mathrm{K}_{\mathrm{i} 1}=4.8 \mathrm{nM}, \mathrm{K}_{\mathrm{i} 2}=105 \mathrm{nM}$

Fig. 4. Competitive binding of amyloid tracers in the frontal cortices and striatum from sporadic and autosomal dominant Alzheimer's disease. (A) ${ }^{3} \mathrm{H}-\mathrm{PIB}(1.0 \mathrm{nM})$ displacement with $10^{-12} \mathrm{M}-10^{-4} \mathrm{M}$ AZD2184 and BTA-1 in the frontal cortices from autosomal dominant Alzheimer's disease (APPswe, PS1 M146V and PS1 EA9 mutation carriers). (B) ${ }^{3} \mathrm{H}-\mathrm{PIB}(1.0 \mathrm{nM})$ displacement with $10^{-12} \mathrm{M}-10^{-4} \mathrm{M}$ AZD2184 and BTA-1 in the striatum from sporadic and autosomal dominant Alzheimer's disease. Binding data were analyzed using GraphPrism non-linear regression fitting. Data are presented as means \pm standard error of the mean (SEM). Abbreviations: sAD, sporadic Alzheimer's disease; ADAD, autosomal dominant Alzheimer's disease; ${ }^{3} \mathrm{H}-\mathrm{PIB},{ }^{3} \mathrm{H}-\mathrm{Pittsburgh}$ compound B.

\subsection{Interaction of resveratrol with amyloid tracers}

binding in the frontal cortex of sporadic Alzheimer's disease

To investigate the possible interactive mechanisms between resveratrol and $A \beta$ tracers' binding sites in sAD brain, competitive binding assays were performed using resveratrol $\left(10^{-11}\right.$ to $\left.10^{-4} \mathrm{M}\right)$ with ${ }^{3} \mathrm{H}-\mathrm{AZD} 2184(1.5$ $\mathrm{nM}),{ }^{3} \mathrm{H}$-PIB $(1.0 \mathrm{nM})$, and ${ }^{3} \mathrm{H}$-florbetaben $(2.0 \mathrm{nM})$, respectively, in homogenates prepared from the frontal cortex of three SAD cases. Analysis of the resveratrol competition binding studies demonstrated an interaction with a high-affinity binding site for ${ }^{3} \mathrm{H}$-AZD2184 $\left(\mathrm{K}_{\mathrm{i}} \approx 5 \mathrm{nM}\right)$, while for ${ }^{3} \mathrm{H}$-florbetaben to a low affinity site $\left(\mathrm{K}_{\mathrm{i}} \approx 238 \mathrm{nM}\right)$ and a very low affinity site for ${ }^{3} \mathrm{H}$ PIB (K $\mathrm{K}_{\mathrm{i}} \approx 1900 \mathrm{nM}$; Fig. 5).

\section{Discussion}

Amyloid PET imaging has advanced our understanding of the early presymptomatic deposition of fibrillar $A \beta$ in patients with ADAD and SAD $[14,18,19]$. There is a need to understand the interaction of $A \beta$ ligands on the different binding sites on the $A \beta$ fibril $\beta$-sheet and to clarify their biological roles and possible technical confounders [20-22]. In this study, we examined the in vitro properties of $A \beta$ tracers and studied how different chemical structures (Fig. 6) could influence the interaction of different $\mathrm{A} \beta$ conformation characteristics in ADAD and SAD cortical and striatal brain tissue, providing a link between binding and $\mathrm{A} \beta$ neuropathology.

Clinical studies using different $A \beta$ PET tracers have shown comparable results in detecting the presence of

Table 2

Regional distribution of amyloid tracer ${ }^{3} \mathrm{H}-\mathrm{PIB}(1.0 \mathrm{nM})$ and ${ }^{3} \mathrm{H}-\mathrm{AZD} 2184$ (1.5 nM) binding in brain from sporadic, autosomal dominant Alzheimer's disease and healthy controls

\begin{tabular}{lllll}
\hline Brain region & Ligand & ADAD & sAD & Control \\
\hline Frontal cortex & ${ }^{3} \mathrm{H}-\mathrm{PIB}(\mathrm{pmol} / \mathrm{g}$ tissue $)$ & $212.2 \pm 46.5^{* *}(\mathrm{n}=5)$ & $219.0 \pm 66.6^{* * *}(\mathrm{n}=8)$ & $15.4 \pm 20.5(\mathrm{n}=14)$ \\
& ${ }^{3} \mathrm{H}-\mathrm{AZD} 2184(\mathrm{pmol} / \mathrm{g}$ tissue $)$ & $409.9 \pm 171.6^{* *}(\mathrm{n}=5)$ & $273.4 \pm 103.7 * * *(\mathrm{n}=8)$ & $19.9 \pm 31.0(\mathrm{n}=14)$ \\
Striatum & ${ }^{3} \mathrm{H}-\mathrm{PIB}(\mathrm{pmol} / \mathrm{g}$ tissue) & $133.7 \pm 43.5^{* * *}(\mathrm{n}=6)$ & $53.7 \pm 68.9^{\#}(\mathrm{n}=7)$ & $5.6 \pm 8.3(\mathrm{n}=8)$ \\
& ${ }^{3} \mathrm{H}-\mathrm{AZD} 2184(\mathrm{pmol} / \mathrm{g}$ tissue) & $237.5 \pm 85.2^{*}(\mathrm{n}=6)$ & $179.7 \pm 172.6(\mathrm{n}=7)$ & $27.7 \pm 32.6(\mathrm{n}=6)$ \\
\hline
\end{tabular}

Abbreviations: sAD, sporadic Alzheimer's disease; ADAD, autosomal dominant Alzheimer's disease; ${ }^{3} \mathrm{H}-\mathrm{PIB},{ }^{3} \mathrm{H}-\mathrm{Pittsburgh}$ compound B.

NOTE. Data are presented as means \pm standard deviation (SD).

NOTE. Significant differences compared to control group (Mann-Whitney $U$ test) are indicated by $* P<.05$, ** $P<.01$, *** $P<.001$. Significant difference between $\mathrm{ADAD}$ and $\mathrm{SAD}$ group is indicated by ${ }^{\#} P<.05$. 


\section{SAD Frontal cortex}
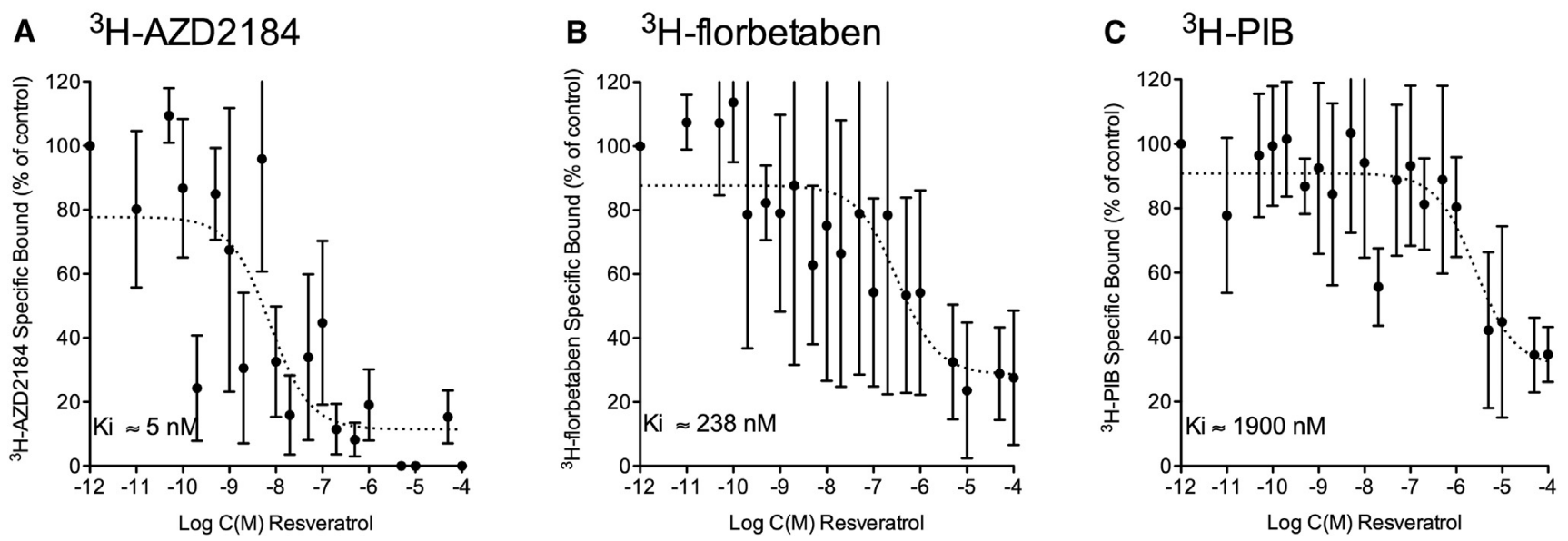

Fig. 5. Effect of resveratrol $\left(10^{-11} \mathrm{M}-10^{-4} \mathrm{M}\right)$ on the amyloid tracers binding in the frontal cortices from sporadic Alzheimer's disease. (A) ${ }^{3} \mathrm{H}-\mathrm{AZD} 2184$ $(1.5 \mathrm{nM}),(B){ }^{3} \mathrm{H}$-PIB $(1.0 \mathrm{nM})$, and $(\mathrm{C})^{3} \mathrm{H}$-florbetaben $(2.0 \mathrm{nM})$, in frontal cortex brain homogenate from sporadic Alzheimer's disease $(\mathrm{n}=3)$. The interaction with resveratrol on ${ }^{3} \mathrm{H}$-AZD2184 was estimated to $\mathrm{Ki} \approx 5 \mathrm{nM},{ }^{3} \mathrm{H}$-florbetaben $\mathrm{Ki} \approx 238 \mathrm{nM}$ and ${ }^{3} \mathrm{H}$-PIB Ki $\approx 1900 \mathrm{nM}$. ${ }^{3} \mathrm{H}$-PIB $={ }^{3} \mathrm{H}$-Pittsburgh compound $\mathrm{B}$; Binding data were analyzed using GraphPrism nonlinear regression fitting. Data are presented as means \pm standard error of the mean (SEM).

fibrillar $\mathrm{A} \beta$ plaques in brain from $\mathrm{SAD}$ and mild cognitive impairment using ${ }^{11} \mathrm{C}$-PIB [23], ${ }^{18} \mathrm{~F}$-florbetaben $[24],{ }^{18} \mathrm{~F}$ florbetapir, ${ }^{18} \mathrm{~F}$-flutemetamol $[25,26]$, and ${ }^{18} \mathrm{~F}-\mathrm{NAV} 4694$ [27]. Head-to-head comparison of ${ }^{11} \mathrm{C}$-PIB and ${ }^{18} \mathrm{~F}$ AZD4694 has shown strong correlation in binding [27] as well as between the three tracers ${ }^{11} \mathrm{C}$-PIB, ${ }^{18} \mathrm{~F}$-florbetapir, and ${ }^{18} \mathrm{~F}$-flutemetamol [28]. In A $\beta$ microPET in transgenic AD rat brain, excessive NAV4694 (an AZD2184 analog) blocked only $10 \%-25 \%{ }^{11} \mathrm{C}$-PIB binding, suggesting that these two tracers may bind to different sites or forms of $A \beta$ [29]. Such competitive experiment is highly informative but not available in $\mathrm{AD}$ patients.

${ }^{3} \mathrm{H}$-PIB binding correlates with amyloid plaque loads in sAD brain [30,31], including neuritic plaques, cerebral angiopathy (CAA), diffuse plaques, but not amorphous amyloid plaques in $\mathrm{AD}$ brain [32]. ${ }^{18} \mathrm{~F}$-flutemetamol [26], ${ }^{18} \mathrm{~F}$-florbetapir [33], and ${ }^{18} \mathrm{~F}$-florbetaben PET have shown high sensitivity and specificity for the detection of histopathology-confirmed neuritic $A \beta$ plaques. A subfraction of $A \beta$ has been found containing high-affinity ${ }^{3} \mathrm{H}$-PIB site in sAD brain [34]. Recent studies reported that Thal phase but not CERAD score correlates with PIB SUV from antemortem imaging, suggesting that diffuse plaques may contribute to the PIB signal in PET imaging [32].

From the chemical structure perspective, Thioflavine Tderived tracer ${ }^{3} \mathrm{H}$-AZD2184, ${ }^{3} \mathrm{H}-\mathrm{PIB}$, methyl- ${ }^{3} \mathrm{H}-\mathrm{BTA}-1$, and stilbene-derived tracer ${ }^{3} \mathrm{H}$-florbetaben all share a planar structure. In addition, florbetaben contains a more flexible polyethylene glycol (PEG) chain, which maintain lipophilicity and neutrality may influence the compounds engagement with $\beta$-sheet structure [35]. All studied $A \beta$ tracers $\left({ }^{3} \mathrm{H}\right.$-florbetaben, $\left.{ }^{3} \mathrm{H}-\mathrm{AZD} 2184,{ }^{3} \mathrm{H}-\mathrm{PIB}\right)$ except ${ }^{3} \mathrm{H}-\mathrm{Me}-\mathrm{BTA}-1$ showed both a high-affinity and a low-affinity binding site in $\mathrm{AD}$ brain tissue, in agreement with earlier studies [7]. AZD2184 showed higher affinity of binding sites in the frontal cortex of SAD and a third binding site in the frontal cortex of ADAD, supporting multiple binding site model on fibrillar $A \beta$ in brain. Earlier biophysical modeling studies have identified six possible binding sites for $A \beta$ tracers PIB, BTA-1, and Thioflavine $\mathrm{T}$ [3,4]. Florbetaben, florbetapir, and PIB that of different scaffolds share a common binding mode to surface groove, whereas the particular binding position and affinity might vary between different amyloid tracers and morphologies of $A \beta$ fibrils [5] which is in line with present study. When the binding profile of AZD2184 and thioflavine was studied by molecular docking and molecular dynamic simulation, four binding sites were observed on the $A \beta$ fibril where three with the fibril and one on the two sides of the Met35 residue on the surface [35]. The binding affinity of AZD2184 was found to be higher than thioflavine due to electrostatic interaction and spatial restriction [35]. Additionally, factors such as lipophilicity, pKa, and the overall tracer structure may influence the tracer binding properties, and the low nonspecific binding of ${ }^{3} \mathrm{H}$-AZD2184 has been attributed partly to its low lipophilicity $\left({ }^{3} \mathrm{H}-\mathrm{AZD} 2184<{ }^{3} \mathrm{H}\right.$-PIB $<{ }^{3} \mathrm{H}$-florbetaben $<$ Methyl- ${ }^{3}$ H-BTA-1) $[36,37]$.

We found that resveratrol interacted with the rank order of AZD2184 > florbetaben > PIB. Several possible mechanisms have been proposed regarding resveratrol-A $\beta$ interaction, including specific conformation or noncovalent interaction with $\beta$-sheet structure [38] or with $A \beta$ sequence such as the $\mathrm{A} \beta_{17-21}$ aromatic phenylalanine residue. Resveratrol are currently under clinical trial and phase II clinical trial in AD patients (NCT01504854). Interestingly enough resveratrol is a phenol with stilbene structure. Resveratrol has been shown to inhibit synthetic $A \beta$ aggregation and 


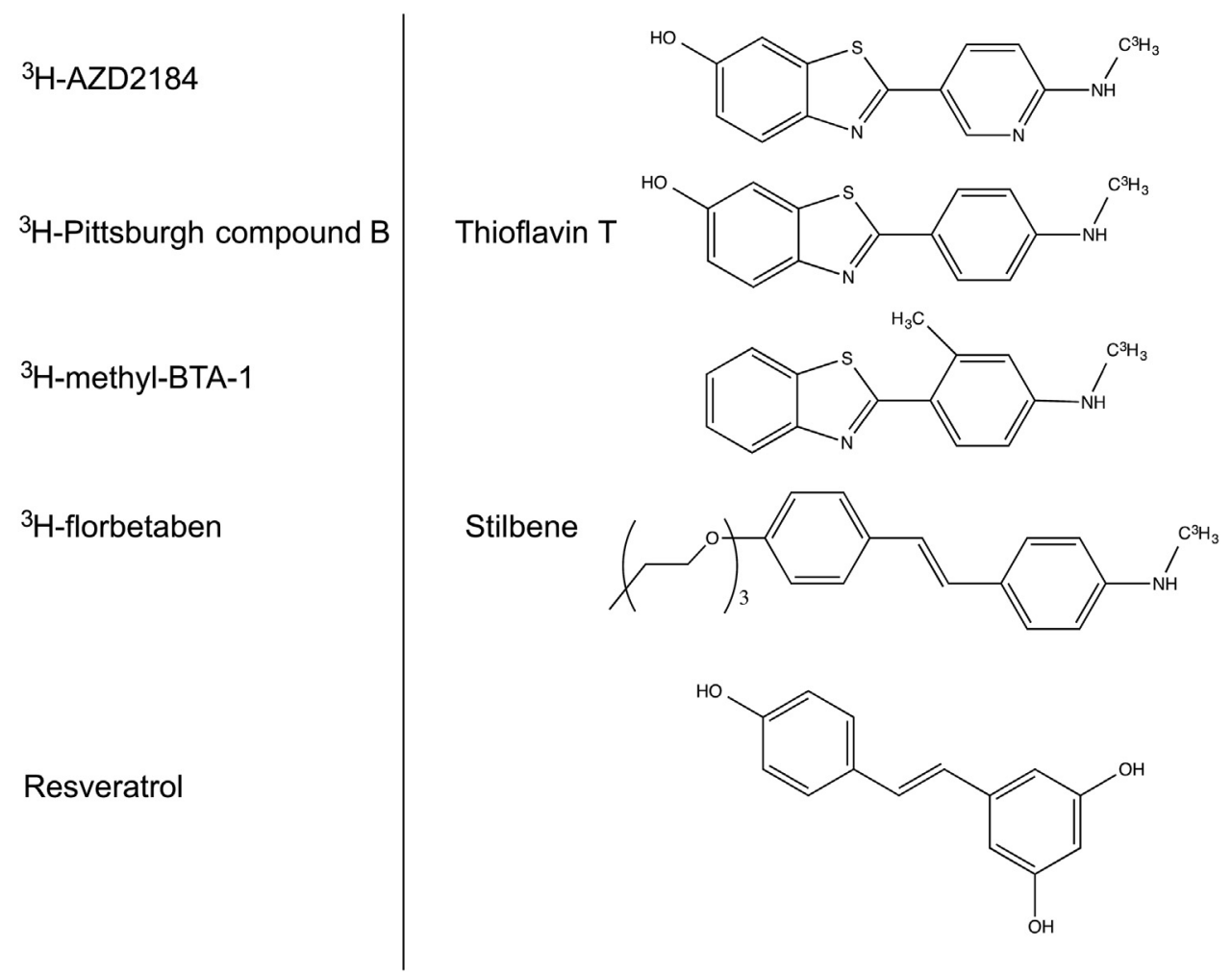

Fig. 6. Chemical structures of different amyloid positron emission tomography (PET) tracers and the polyphenol resveratrol.

toxicity in vitro [39] and detected fluorescence of $A \beta$ plaques similarly as Thioflavin $\mathrm{T}$ in postmortem $\mathrm{AD}$ brain slides $[40,41]$. The indication of direct binding of resveratrol to $\mathrm{A} \beta$ has raised an interest in developing resveratrol derivatives as potential A $\beta$ PET tracers [42], luminescent conjugated polymers as well as AD treatment agents. In a recent study, administration of resveratrol $(200 \mathrm{mg} / \mathrm{day})$ for 26 weeks in healthy, overweight older adult showed an improvement in memory performance as well as improved glucose metabolism [43].

Recent Alzheimer Disease Neuroimaging Initiative study and Dominantly Inherited Alzheimer Network have identified higher total $A \beta$ load and less variety in comorbidity in ADAD brain [44]. We examined the properties of different $A \beta$ tracers in brain tissue from mutation carriers with different characteristic AD pathology [45-49] and compared with that in SAD. We demonstrated that the number of striatal ${ }^{3} \mathrm{H}-\mathrm{PIB}$ and ${ }^{3} \mathrm{H}-\mathrm{AZD} 2184$ binding sites in ADAD was higher compared to SAD and did not differ in the frontal cortex between two AD groups. This observation is in agreement with an earlier report [10], which also demonstrated a higher ${ }^{11} \mathrm{C}$-PIB retention in vivo in the striatum of PSI EA9 mutation carriers compared to $\mathrm{SAD}$. The lower intensity of silver impregnation of the plaques (mainly diffuse) in the striatum of $P S 1$ $E \Delta 9$ mutation case underlines the unique biochemical feature of the fibrillation of that mutation. PSI EA9 muta- tion carriers are known for their characteristic pathology of "cotton wool" plaques and CAA in the frontal cortex and widespread small diffuse $A \beta$ plaques devoid of dystrophic neurites in the striatum [48]. The finding suggests that $A \beta$ tracers can detect diffuse plaques. The arctic $A P P$ mutation carriers are lacking the $\beta$-sheet formation and show low ${ }^{11} \mathrm{C}$-PIB brain retention [13]. A very high plaque load is presented in the APPswe and PS1 M146V brain tissue. Despite that $A \beta$ tracers have been suggested to bind to late fibrillar forms, the findings in the present study suggest that intensity of the binding thus not only depends on the morphological feature of the silver impregnation but probably rather more on the specific biochemical properties of plaques especially in the particular mutation, and the sensitivity of the ligand binding even to the mutation-specific earlier/diffuse plaque.

There are some limitations of this study. First, the fact that the availably of autopsy brain material is rare from these very unusual mutations which does not allow largescale studies. Second, in vitro solid-state nuclear magnetic resonance studies suggest that the molecular structures of $\mathrm{A} \beta$ fibrils vary in different sAD brains, which may contribute to the observed variation [50]. For quality control of the present study, the experiments were therefore repeated independently more than five times and the binding curve analysis was evaluated independently and discussed between three of the authors. Third, the variance 
in the competitive binding studies with resveratrol and different amyloid tracer was rather large as resveratrol is not specific for $\mathrm{A} \beta$ fibrils.

Understanding the binding mode of different amyloid tracers to brain $A B$ aggregates may facilitate the development of new early biomarkers as well as designing new drug targets for AD therapies. Future study regarding the pathologic properties of the arctic and E293 $\Delta$ mutations brains including studies of regional tau deposition and astrocytes activation will be insightful. New strategies for developing new $A ß$ tracers that can detect smaller forms of $A B$ oligomeric forms as well protofibril are of great interest and should be tested in in silico modeling as well as in ADAD especially arctic mutation brain tissue and further also be explored by in vivo imaging in ADAD subjects at risk as well as SAD patients. Competitive binding using different amyloid compounds in vivo in AD patients would be informative but might be difficult due to the high concentrations needed of the tracers. In addition, it will be of clinical relevance to study how differences in properties of amyloid tracers could discriminate between rapidly compared to slowly progressive AD cases and also might detect variants of late-onset $\mathrm{SAD}$ with divergent $\mathrm{A} ß$ pathology.

To conclude, the assessed $A \beta$ tracers in the present study showed multiple binding sites and different binding properties in ADAD in comparison to SAD brains. AZD2184 detected a third $A \beta$ binding site in the ADAD frontal cortex. High binding of the A $\beta$ tracers in ADAD striatal tissue suggests conformal differences of amyloid aggregates in ADAD compared to $\mathrm{SAD}$, confirming earlier in vivo $\mathrm{PET}$ observations in the cortex and striatum of SAD and ADAD patients. The antiamyloid phenol compound resveratrol interacted in nanomolar range with AZD2184 but showed less affinity to florbetaben followed by PIB. Studies of the target similarity, differences, and selectivity properties between different amyloid tracers, and in vivo/postmortem validation will facilitate the development of new imaging and therapeutic agents action on specific $\mathrm{A} ß$ conformational aggregates.

\section{Acknowledgments}

This work was supported by grants from the Swedish Research Council (project 05817), Swedish Foundation for Strategic Research (SSF), Karolinska Institutet Strategic Neuroscience program, the Stockholm County Council-Karolinska Institutet regional agreement on medical training and clinical research (ALF grant), Swedish Brain Power, the Swedish Brain Foundation, the Alzheimer Foundation in Sweden, European Union's Seventh Framework Programme (FP7/2007-2013) under grant agreement no HEALTH-F2-2011-278850 (INMiND), the Foundation for Old Servants, Karolinska Institutet's Foundation for Aging Research, Gun and Bertil Stohne's Foundation, Sigurd and Elsa Golje's Foundation, Ragn- hild and Einar Lundström's Memorial Foundation, Demensfonden.

\section{RESEARCH IN CONTEXT}

1. Systematic review: Literature search using autosomal dominant Alzheimer's disease (ADAD), sporadic Alzheimer's disease (sAD), amyloid- $\beta$ imaging. In silico studies indicate that different amyloid tracers might bind to different site on the amyloid beta sheets. The aim of the study was to characterize the binding properties of amyloid tracers in ADAD brain in comparison to SAD.

2. Interpretation: Amyloid tracers such as ${ }^{3} \mathrm{H}-\mathrm{PIB},{ }^{3} \mathrm{H}-$ florbetaben, ${ }^{3} \mathrm{H}$-AZD2184 and BTA-1 share a highaffinity binding site and a large variation in affinity of low-affinity binding site in SAD cases. A highaffinity binding site is observed in ADAD striatal tissue and a third binding sites for ${ }^{3} \mathrm{H}-\mathrm{AZD} 2184$ in the frontal cortex compared to SAD. The polyphenol resveratrol showed highest interaction with AZD2184 binding (nanomolar range). The findings suggest that the amyloid tracer binding depends both on the tracer structure as well as the amyloid- $\beta$ fibrils conformations.

3. Future directions: Further studies regarding amyloid$\beta$ polymorphism and differences between $\mathrm{ADAD}$ and sAD.

\section{References}

[1] Dubois B, Feldman HH, Jacova C, Hampel H, Molinuevo JL, Blennow K, et al. Advancing research diagnostic criteria for Alzheimer's disease: the IWG-2 criteria. Lancet Neurol 2014; 13:614-29.

[2] Liu E, Schmidt ME, Margolin R, Sperling R, Koeppe R, Mason NS, et al. Amyloid-beta 11C-PiB-PET imaging results from 2 randomized bapineuzumab phase 3 AD trials. Neurology 2015;85:692-700.

[3] Wu C, Bowers Michael T, Shea JE. On the origin of the stronger binding of PIB over thioflavin T to protofibrils of the Alzheimer amyloid- $\beta$ peptide: A molecular dynamics study. Biophys J 2011;100:1316-24.

[4] Murugan NA, Olsen JM, Kongsted J, Rinkevicius Z, Aidas K, Ågren H. Amyloid fibril-induced structural and spectral modifications in the thioflavin-T optical probe. J Phys Chem Lett 2012;4:70-7.

[5] Skeby KK, Sørensen J, Schiøtt B. Identification of a common binding mode for imaging agents to amyloid fibrils from molecular dynamics simulations. J Am Chem Soc 2013;135:15114-28.

[6] Ye L, Morgenstern JL, Gee AD, Hong G, Brown J, Lockhart A. Delineation of Positron Emission Tomography Imaging Agent Binding Sites on $\beta$-Amyloid Peptide Fibrils. J Biol Chem 2005;280:23599-604.

[7] Ni R, Gillberg PG, Bergfors A, Marutle A, Nordberg A. Amyloid tracers detect multiple binding sites in Alzheimer's disease brain tissue. Brain 2013;136:2217-27. 
[8] Bettens K, Sleegers K, Van Broeckhoven C. Genetic insights in Alzheimer's disease. Lancet Neurol 2013;12:92-104.

[9] Klunk WE, Price JC, Mathis CA, Tsopelas ND, Lopresti BJ, Ziolko SK, et al. Amyloid deposition begins in the striatum of presenilin-1 mutation carriers from two unrelated pedigrees. J Neurosci 2007;27:6174-84.

[10] Koivunen J, Verkkoniemi A, Aalto S, Paetau A, Ahonen JP, Viitanen M, et al. PET amyloid ligand [11C]PIB uptake shows predominantly striatal increase in variant Alzheimer's disease. Brain 2008;131:1845-53.

[11] Villemagne VL, Ataka S, Mizuno T, Brooks WS, Wada Y, Kondo M, et al. High striatal amyloid beta-peptide deposition across different autosomal Alzheimer disease mutation types. Arch Neurol 2009; 66:1537-44.

[12] Knight WD, Okello AA, Ryan NS, Turkheimer FE, Rodriguez Martinez de Llano S, Edison P, et al. Carbon-11-Pittsburgh compound B positron emission tomography imaging of amyloid deposition in presenilin 1 mutation carriers. Brain 2010;134:293-300.

[13] Scholl M, Wall A, Thordardottir S, Ferreira D, Bogdanovic N, Langstrom B, et al. Low PiB PET retention in presence of pathologic CSF biomarkers in Arctic APP mutation carriers. Neurology 2012; 79:229-36.

[14] Bateman RJ, Xiong C, Benzinger TL, Fagan AM, Goate A, Fox NC, et al. Clinical and biomarker changes in dominantly inherited Alzheimer's disease. N Engl J Med 2012;367:795-804.

[15] Fleisher AS, Chen K, Quiroz YT, Jakimovich LJ, Gomez MG, Langois CM, et al. Florbetapir PET analysis of amyloid-beta deposition in the presenilin 1 E280A autosomal dominant Alzheimer's disease kindred: a cross-sectional study. Lancet Neurol 2012; 11:1057-65.

[16] Tomiyama T, Nagata T, Shimada H, Teraoka R, Fukushima A, Kanemitsu H, et al. A new amyloid beta variant favoring oligomerization in Alzheimer's-type dementia. Ann Neurol 2008;63:377-87.

[17] Bogdanovic N, Corder E, Lannfelt L, Winblad B. APOE polymorphism and clinical duration determine regional neuropathology in Swedish APP 670,671$)$ mutation carriers: implications for lateonset Alzheimer's disease. J Cell Mol Med 2002;6:199-214.

[18] Ossenkoppele R, Jansen WJ, Rabinovici GD, Knol DL, van der Flier WM, van Berckel BN, et al. Prevalence of amyloid PET positivity in dementia syndromes: a meta-analysis. JAMA 2015;313:1939-49.

[19] Scholl M, Carter SF, Westman E, Rodriguez-Vieitez E, Almkvist O, Thordardottir S, et al. Early astrocytosis in autosomal dominant Alzheimer's disease measured in vivo by multi-tracer positron emission tomography. Sci Rep 2015;5:16404.

[20] Schmidt ME, Chiao P, Klein G, Matthews D, Thurfjell L, Cole PE, et al. The influence of biological and technical factors on quantitative analysis of amyloid PET: Points to consider and recommendations for controlling variability in longitudinal data. Alzheimers Dement 2015; 11:1050-68.

[21] Kepe V, Moghbel MC, Langstrom B, Zaidi H, Vinters HV, Huang SC, et al. Amyloid-beta positron emission tomography imaging probes: a critical review. J Alzheimers Dis 2013;36:613-31.

[22] Cole GB, Keum G, Liu J, Small GW, Satyamurthy N, Kepe V, et al. Specific estrogen sulfotransferase (SULT1E1) substrates and molecular imaging probe candidates. Proc Natl Acad Sci U S A 2010; 107:6222-7.

[23] Forsberg A, Engler H, Almkvist O, Blomquist G, Hagman G, Wall A, et al. PET imaging of amyloid deposition in patients with mild cognitive impairment. Neurobiol Aging 2008;29:1456-65.

[24] Villemagne VL, Mulligan RS, Pejoska S, Ong K, Jones G, O'Keefe G, et al. Comparison of 11C-PiB and 18F-florbetaben for Abeta imaging in ageing and Alzheimer's disease. Eur J Nucl Med Mol Imaging 2012; 39:983-9.

[25] Vandenberghe R, Van Laere K, Ivanoiu A, Salmon E, Bastin C, Triau E, et al. 18F-flutemetamol amyloid imaging in Alzheimer disease and mild cognitive impairment: A phase 2 trial. Ann Neurol 2010;68:319-29.
[26] Curtis C, Gamez JE, Singh U, Sadowsky CH, Villena T, Sabbagh MN, et al. Phase 3 trial of flutemetamol labeled with radioactive fluorine 18 imaging and neuritic plaque density. JAMA Neurol 2015;72:287-94.

[27] Rowe CC, Pejoska S, Mulligan RS, Jones G, Chan JG, Svensson S, et al. Head-to-head comparison of 11C-PiB and 18F-AZD4694 (NAV4694) for beta-amyloid imaging in aging and dementia. J Nucl Med 2013;54:880-6.

[28] Landau SM, Thomas BA, Thurfjell L, Schmidt M, Margolin R, Mintun M, et al. Amyloid PET imaging in Alzheimer's disease: a comparison of three radiotracers. Eur J Nucl Med Mol Imaging 2014; 41:1398-407.

[29] Parent M, Zimmer ER, Shin M, Kang M, DoCarmo S, Aliaga A, et al. Competitive binding of [11C]PIB and [18F]NAV4694 in a transgenic rat model of amyloidosis. Alzheimers Dement 2014;10:P893.

[30] Kadir A, Marutle A, Gonzalez D, Scholl M, Almkvist O, Mousavi M, et al. Positron emission tomography imaging and clinical progression in relation to molecular pathology in the first Pittsburgh Compound B positron emission tomography patient with Alzheimer's disease. Brain 2010;134:301-17.

[31] Niedowicz DM, Beckett TL, Matveev S, Weidner AM, Baig I, Kryscio RJ, et al. Pittsburgh compound B and the postmortem diagnosis of Alzheimer disease. Ann Neurol 2012;72:564-70.

[32] Lockhart A, Lamb JR, Osredkar T, Sue LI, Joyce JN, Ye L, et al. PIB is a non-specific imaging marker of amyloid-beta (Abeta) peptiderelated cerebral amyloidosis. Brain 2007;130:2607-15.

[33] Clark CM, Pontecorvo MJ, Beach TG, Bedell BJ, Coleman RE, Doraiswamy PM, et al. Cerebral PET with florbetapir compared with neuropathology at autopsy for detection of neuritic amyloidbeta plaques: a prospective cohort study. Lancet Neurol 2012; 11:669-78.

[34] Matveev SV, Spielmann HP, Metts BM, Chen J, Onono F, Zhu H, et al. A distinct subfraction of Abeta is responsible for the high-affinity Pittsburgh compound B-binding site in Alzheimer's disease brain. J Neurochem 2014;131:356-68.

[35] Kung HF, Choi SR, Qu W, Zhang W, Skovronsky D. 18F stilbenes and styrylpyridines for PET imaging of A beta plaques in Alzheimer's disease: a miniperspective. J Med Chem 2010;53:933-41.

[36] Neumaier B, Deisenhofer S, Furst D, von Arnim CA, Thees S, Buck AK, et al. Radiosynthesis and evaluation of [11C]BTA-1 and [11C]3'-Me-BTA-1 as potential radiotracers for in vivo imaging of beta-amyloid plaques. Nuklearmedizin 2007;46:271-80.

[37] Forsberg A, Jureus A, Cselenyi Z, Eriksdotter M, Freund-Levi Y, Jeppsson F, et al. Low background and high contrast PET imaging of amyloid-beta with [11C]AZD2995 and [11C]AZD2184 in Alzheimer's disease patients. Eur J Nucl Med Mol Imaging 2013; 40:580-93.

[38] Porat Y, Abramowitz A, Gazit E. Inhibition of amyloid fibril formation by polyphenols: structural similarity and aromatic interactions as a common inhibition mechanism. Chem Biol Drug Des 2006;67:27-37.

[39] Ladiwala AR, Lin JC, Bale SS, Marcelino-Cruz AM, Bhattacharya M, Dordick JS, et al. Resveratrol selectively remodels soluble oligomers and fibrils of amyloid Abeta into off-pathway conformers. J Biol Chem 2010;285:24228-37.

[40] Ahn JS, Lee JH, Kim JH, Paik SR. Novel method for quantitative determination of amyloid fibrils of alpha-synuclein and amyloid beta/A4 protein by using resveratrol. Anal Biochem 2007;367:259-65.

[41] La Joie R, Perrotin A, Barre L, Hommet C, Mezenge F, Ibazizene M, et al. Region-specific hierarchy between atrophy, hypometabolism, and beta-amyloid (abeta) load in Alzheimer's disease dementia. J Neurosci 2012;32:16265-73.

[42] Lee I, Choe YS, Choi JY, Lee KH, Kim BT. Synthesis and evaluation of (1)(8)F-labeled styryltriazole and resveratrol derivatives for betaamyloid plaque imaging. J Med Chem 2012;55:883-92.

[43] Witte AV, Kerti L, Margulies DS, Floel A. Effects of resveratrol on memory performance, hippocampal functional connectivity, and glucose metabolism in healthy older adults. J Neurosci 2014; $34: 7862-70$. 
[44] Cairns NJ, Perrin RJ, Franklin EE, Carter D, Vincent B, Xie M, et al. Neuropathologic assessment of participants in two multi-center longitudinal observational studies: the Alzheimer Disease Neuroimaging Initiative (ADNI) and the Dominantly Inherited Alzheimer Network (DIAN). Neuropathology 2015;35:390-400.

[45] Haltia M, Viitanen M, Sulkava R, Ala-Hurula V, Poyhonen M, Goldfarb L, et al. Chromosome 14-encoded Alzheimer's disease: genetic and clinicopathological description. Ann Neurol 1994;36:362-7.

[46] Lannfelt L, Bogdanovic N, Appelgren H, Axelman K, Lilius L, Hansson G, et al. Amyloid precursor protein mutation causes Alzheimer's disease in a Swedish family. Neurosci Lett 1994;168:254-6.

[47] Houlden H, Baker M, McGowan E, Lewis P, Hutton M, Crook R, et al. Variant Alzheimer's disease with spastic paraparesis and cotton wool plaques is caused by PS-1 mutations that lead to exceptionally high amyloid-beta concentrations. Ann Neurol 2000;48:806-8.

[48] Verkkoniemi A, Kalimo H, Paetau A, Somer M, Iwatsubo T, Hardy J, et al. Variant Alzheimer disease with spastic paraparesis: neuropathological phenotype. J Neuropathol Exp Neurol 2001; 60:483-92.

[49] Crook R, Verkkoniemi A, Perez-Tur J, Mehta N, Baker M, Houlden H, et al. A variant of Alzheimer's disease with spastic paraparesis and unusual plaques due to deletion of exon 9 of presenilin 1. Nat Med 1998; 4:452-5.

[50] Lu JX, Qiang W, Yau WM, Schwieters CD, Meredith SC, Tycko R. Molecular structure of beta-amyloid fibrils in Alzheimer's disease brain tissue. Cell 2013;154:1257-68.

\section{Did you know?}

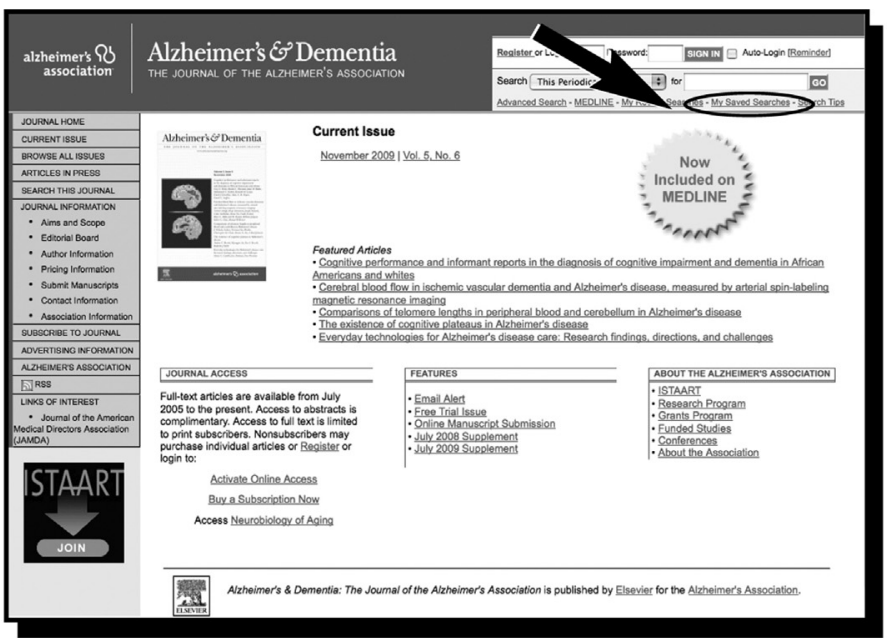

You can save your online

searches and get the results

by email.

\section{Visit www.alzheimersanddementia.org today!}

